\title{
Resistin Is a Novel Biomarker for a Risk of Heart Failure
}

\section{Yasuchika Takeishi*}

Department of Cardiology and Hematology, Fukushima Medical University, Fukushima, Japan

\begin{abstract}
Resistin is derived mainly from fat tissue in rodents, and serum levels are elevated in animal models of obesity and insulin resistance. Recent clinical studies have demonstrated that circulating resistin is associated with inflammation, coronary atherosclerosis, renal dysfunction, adverse prognosis in patients with atherothrombotic ischemic stroke and heart failure. In the population-based observational study, increased circulating levels of resistin are associated with incidence of new-onset heart failure, even after accounting for prevalent coronary heart disease, obesity, insulin resistance, and inflammation. In the elderly, incident heart failure rates (per 1000 person-years) elevate with increasing baseline resistin concentrations. In addition, resistin is strongly associated with risk for incident heart failure in Cox proportional hazard models controlling for clinical variables, inflammatory biomarkers, and measures of adiposity.
\end{abstract}

Keywords: Adipocytokine; Prognosis; Inflammation; Insulin resistance

\section{Multiple Biological Functions of Resistin}

Adipose tissue is not only a store of excess energy but also a highly active endocrine organ [1-4]. Adipose tissue secretes bioactive peptides, termed "adipocytokines", which act on the function and structural integrity of various tissues through autocrine, paracrine and endocrine mechanisms [1-4]. Increased production of adipocytokines impacts on multiple functions such as energy balance, immunity, insulin sensitivity, angiogenesis, blood pressure, lipid metabolism, inflammation and haemostasis, all of which are closely linked with cardiovascular diseases. Leptin, a 167-amino acid protein, is expressed exclusively by adipose tissue. Leptin is a fundamental signal of satiety to the brain and a regulator of insulin and glucose metabolism. Adiponectin, one of the most abundant adipocytokines, is a 244 -amino acid protein produced by the apM1 gene, highly expressed in human adipose tissue. Adiponectin has anti-atherogenic and anti-inflammatory properties. Resistin is a novel cysteine-rich secretory $12.5-\mathrm{kDa}$ polypeptide [59]. Resistin was initially identified in the adipose tissue and derived almost exclusively from fat tissue in rodents. However, it is now recognized that resistin is produced from other types of cells including macrophages [10]. Adipose expression and serum levels of resistin are elevated in animal models of obesity and insulin resistance [9]. Although functional roles of resistin are not clearly established, high serum levels of resistin impair glucose tolerance and induce insulin resistance in rats [11]. On the other hand, mice deficient in resistin are protected from obesity-associated insulin resistance [12]. A clinical study has demonstrated that plasma resistin levels are correlated with markers of inflammation and are predictive of coronary atherosclerosis in humans [13]. In addition, resistin concentrations are correlated with renal dysfunction [14] and adverse prognosis in patients with atherothrombotic ischemic stroke [15].

\section{Circulating Concentration of Resistin in Patients with Heart Failure}

Several inflammatory biomarkers including C-reactive protein, interleukin-6, tumor necrosis factor- $\alpha$, pentraxin 3 and etc. are associated with increased risk of heart failure [16]. Similarly, it has been reported that insulin resistance is observed in heart failure. Heart failure is the major and increasing health problem with a high mortality rate, because of the increase in aging population and high prevalence of heart failure in the elderly [17-19]. However, the relationship between resistin and heart failure has not been fully understood.

Takeishi et al. initially reported the association between circulating concentrations of resistin and heart failure [20]. We prospectively enrolled 126 consecutive patients with chronic heart failure $(76$ men, mean age $67 \pm 13$ years) admitted to our hospital. Blood samples were obtained at admission to measure serum resistin levels in 126 patients with heart failure and 18 control subjects. Serum resistin concentrations were measured by a sandwich enzyme-linked immunosorbent assay (ELISA, Phoenix Pharmaceutical, Inc., Belmont, CA, USA). The etiologies of heart failure were dilated cardiomyopathy in 48 patients, ischemic heart disease in 34 patients, valvular heart disease in 20 patients, and hypertensive heart disease in 12 patients. Patients were followed up (mean follow-up $645 \pm 644$ days, range 29 to 1080 days) after discharge to register 1) cardiac death, defined as death from worsening heart failure or sudden cardiac death and 2) worsening heart failure requiring readmission. Serum resistin levels increased with advancing New York Heart Association (NYHA) functional class. Normal upper limit of resistin levels was defined as mean $+2 \mathrm{SD}$ value of 18 control subjects $(14.1 \mathrm{ng} / \mathrm{ml})$. There were 32 patients with high resistin level $(>14.1 \mathrm{ng} / \mathrm{ml})$ and 94 patients with low resistin level $(<$ $14.1 \mathrm{ng} / \mathrm{ml}$ ). Serum resistin levels were not correlated with body mass index and blood glucose. Serum resistin levels were not different between patients with and without diabetes mellitus. There were 31 cardiac events including 10 cardiac deaths and 21 re-hospitalization due to worsening heart failure during the follow-up period. Cardiac event rate was significantly higher in patients with high resistin than in those with low resistin levels $(43.8 \%$ vs. $18.1 \%, \mathrm{P}<0.0036$ by chisquare test). Kaplan-Meier survival analysis also demonstrated that high resistin group showed significantly lower event-free rate than low resistin group $(\mathrm{P}=0.0041$ by $\log$ rank test $)$.Next, patients were divided

*Corresponding author: Yasuchika Takeishi, Department of Cardiology and Hematology, Fukushima Medical University, Hikarigaoka, Fukushima 960-1295, Japan, Tel: +81-24-547-1188; Fax: +81-24-548-1821; E-mail: takeishi@fmu.ac.jp

Received August 22, 2013; Accepted August 24, 2013; Published August 31, 2013

Citation: Takeishi Y (2013) Resistin Is a Novel Biomarker for a Risk of Heart Failure. J Cardiovasc Dis Diagn 1: 122. doi:10.4172/2329-9517.1000122

Copyright: (c) 2013 Takeishi Y. This is an open-access article distributed under the terms of the Creative Commons Attribution License, which permits unrestricted use, distribution, and reproduction in any medium, provided the original author and source are credited. 
into 4 groups based on the serum resistin levels: $1^{\text {st }}$ quartile $(1.7-6.6 \mathrm{ng} /$ $\mathrm{ml}, \mathrm{n}=31), 2^{\text {nd }}$ quartile $(6.7-10.1 \mathrm{ng} / \mathrm{ml}, \mathrm{n}=31), 3^{\text {rd }}$ quartile $(10.2-14.0$ $\mathrm{ng} / \mathrm{ml}, \mathrm{n}=31)$ and $4^{\text {th }}$ quartile $(14.1-60.2 \mathrm{ng} / \mathrm{ml}, \mathrm{n}=33)$. The highest $4^{\text {th }}$ quartile of resistin was associated with the highest risk of cardiac events compared to other 3 groups ( $1^{\text {st }}$ quartile $16.1 \%, 2^{\text {nd }}$ quartile $16.1 \%, 3^{\text {rd }}$ quartile $22.6 \%$ and $4^{\text {th }}$ quartile $\left.42.4 \%\right)$. To determine risk factors to predict cardiac events, we performed the Cox proportional hazard regression analyses. In the univariate analysis, serum resistin level (per one SD increase, Hazard Ratio [HR] 1.357, 95\% Confidence Interval [CI] 1.061-1.746, $\mathrm{P}=0.014$ ) as well as age, body mass index, B-type natriuretic peptide, and the use of loop diuretics were associated with cardiac death and re-hospitalization. Among those variables with $P$ value of less than 0.05 in the univariate analysis, the multivariate Cox proportional hazard regression analysis demonstrated that resistin was an independent predictor for cardiac events in patients with chronic heart failure (HR 1.439, 95\%CI 1.017-2.059, P = 0.041). We concluded that resistin is useful for risk stratification of patients with chronic heart failure and may represent a novel link between metabolic signals and heart failure.

Although patientswith heartfailure developmetabolicderangements including increased adipokine levels and insulin resistance, the relation of resistin with body mass index, blood glucose and diabetes mellitus was not evident in a study by Takeishi et al. [20]. Recently, Schulze et al. measured plasma resistin levels and Homeostasis Model Assessment of Insulin Resistance (HOMA-IR) in acute decompensated heart failure $(\mathrm{n}=44)$, chronic stable heart failure $(\mathrm{n}=26)$ and 21 control subjects [21]. Resistin was elevated in chronic stable heart failure and increased further in acute decompensated heart failure compared to control. Similarly, HOMA-IR was increased in chronic stable heart failure and increased further in acute decompensated heart failure. HOMA-IR correlated positively with resistin levels in heart failure patients. They concluded that acute decompensated heart failure is associated with worsening of insulin resistance and elevation of resistin compared to chronic stable condition.

\section{Association of Resistin with the Incidence of New-Onset Heart Failure}

Frankel et al. have reported the association of resistin with the incidence of heart failure in 2,739 participants in the Framingham Offspring Study [22]. During 6 years of follow-up, 58 participants developed new-onset heart failure. In proportional hazard models adjusting for age, sex, blood pressure, anti-hypertensive treatment, diabetes, smoking, cholesterol, prevalent coronary heart disease, valvular heart disease, left ventricular hypertrophy and estimated glomerular filtration rate, the hazard ratios for heart failure in the middle and top thirds of resistin levels were 2.89 (95\%CI 1.05-7.92) and 4.01 (95\%CI 1.52-10.57) compared to the lowest third. In the maximally adjusted model including C-reactive protein and B-type natriuretic peptide, one SD increment in resistin level $(7.45 \mathrm{ng} / \mathrm{mL})$ was associated with a $26 \%$ increase in heart failure risk (95\%CI 1-60\%). Interestingly, concentrations of adiponectin were not related to heart failure. This was the first report demonstrating that increased circulating levels of resistin were associated with incidence of new-onset heart failure, even after accounting for prevalent coronary heart disease, obesity, insulin resistance, and inflammation.

\section{Resistin as a Risk of Heart Failure}

Heart failure is common disease in the elderly [17,18,23]. In the sub-analysis of the Health $\mathrm{ABC}$ study, Buttler et al. reported the association between serum resistin concentrations at baseline and development of new-onset heart failure among older persons [24]. Out of 3,705 participants enrolled in the Health ABC study, participants with heart failure or missing data for heart failure at baseline were excluded, and 2,902 participants without prevalent heart failure who had available data of serum resistin concentrations were investigated. Their mean age was $73.6 \pm 2.9$ years with $48.1 \%$ men and $58.8 \%$ white. Mean resistin concentration was $20.3 \pm 10.0 \mathrm{ng} / \mathrm{mL}$. They also measured serum concentrations of inflammatory markers (C-reactive protein, interleukin-6, and tumor necrosis factor- $\alpha$ ), insulin resistance (fasting insulin and hemoglobin $\mathrm{A}_{1 \mathrm{C}}$ ) and adopokines (leptin and adiponectin). Total fat mass was assessed by whole-body dual X-ray absorptiometry and abdominal visceral and subcutaneous adipose tissue areas were measured with computed tomography. During median follow-up of 9.4 years, 341 participants $(11.8 \%)$ developed heart failure. Figure 1 shows the observed heart failure incidence in the cohort in relation to baseline resistin concentrations. Incident heart failure rates (per 1,000 person-years) elevated with increasing baseline resistin concentrations. In addition, resistin was strongly associated with risk for incident heart failure in Cox proportional hazard models controlling for clinical variables, inflammatory biomarkers, and measures of adiposity (HR 1.15 per $10.0 \mathrm{ng} / \mathrm{mL}$ increase, $95 \% \mathrm{CI} 1.05-1.27, \mathrm{P}=0.003$ ). They concluded that serum resistin concentrations are independently associated with risk of heart failure in older persons.

Zhang et al. have recently reported the prognostic significance of resistin in ambulatory patients with stable coronary heart disease [25]. This was performed as a sub-analysis of the heart and soul study, and they evaluated whether resistin was predictive of worse cardiovascular outcomes in 980 patients with documented coronary heart disease and stable condition. After a mean follow-up period of 6.1 years, 358 were hospitalized for myocardial infarction or heart failure or had died. As compared to the lowest quartile, patients with resistin levels in the highest quartile were associated with an increased risk of heart failure (HR 2.06, 95\%CI 1.26-3.39) and death (HR 1.56, 95\%CI 1.112.18). However, resistin levels were not associated with a risk of nonfatal myocardial infarction. Resistin was associated with higher risk for heart failure and death, but not myocardial infarction, in ambulatory patients with stable coronary heart disease.

In the Framingham Offspring cohort, Rienstra et al. recently studied the relations between circulating concentrations of resistin

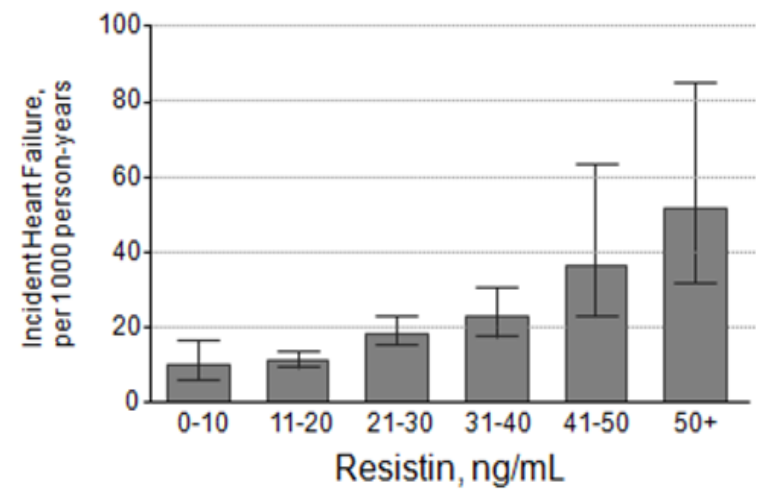

Figure 1: Baseline resistin concentrations and incident heart failure rates (per 1,000 person-years) among 2,902 pertcipants without prevalent heart failure at baseline in the Health ABC Study, which enrolledwell-functioning, community-dwelling individuals aged 70 to 79 years. Error bars represent $95 \%$ confidence interval. (Cited with permission from reference \#24) 
and incident atrial fibrillation or atrial flutter (AF) [26]. Out of 2,487 participants, 206 individuals developed incident AF during a mean follow-up of 7.6 years. Natural logarithmically transformed concentrations of plasma resistin were significantly associated with incident AF. Multivariate-adjusted hazard ratio was 1.17 per one SD increase $(0.41 \mathrm{ng} / \mathrm{mL})$ of logarithmically transformed resistin $(95 \%$ CI 1.02-1.34, $\mathrm{P}=0.028$ ). However, further adjustment for C-reactive protein, the resistin-AF association was attenuated (HR 1.14, 95\% CI $0.99-1.31, \mathrm{P}=0.073)$. In this community-based longitudinal study, higher concentrations of resistin were associated with incident AF, but the relation was attenuated upon adjustment for CRP. Tachycardia due to $\mathrm{AF}$ is one of the major causes of heart failure, especially heart failure with preserved ejection fraction, and patients of heart failure with preserved ejection fraction are increasing. Thus, circulating resistin level may have important clinical implications in heart failure.

\section{References}

1. $\mathrm{Yu} \mathrm{YH}$, Ginsberg HN (2005) Adipocyte signaling and lipid homeostasis: sequelae of insulin-resistant adipose tissue. Circ Res 96: 1042-1052.

2. Petersen KF, Shulman GI (2006) Etiology of insulin resistance. Am J Med 119: S10-16.

3. Rondinone CM (2006) Adipocyte-derived hormones, cytokines, and mediators Endocrine 29: 81-90.

4. Ronti T, Lupattelli G, Mannarino E (2006) The endocrine function of adipose tissue: an update. Clin Endocrinol (Oxf) 64: 355-365.

5. BeÅ,towski J (2003) Adiponectin and resistin--new hormones of white adipose tissue. Med Sci Monit 9: RA55-61.

6. Kunnari A, Ukkola O, Kesäniemi YA (2005) Resistin polymorphisms are associated with cerebrovascular disease in Finnish Type 2 diabetic patients. Diabet Med 22: 583-589.

7. Díez JJ, Iglesias P, Fernández-Reyes MJ, Aguilera A, Bajo MA, et al. (2005) Serum concentrations of leptin, adiponectin and resistin, and their relationship with cardiovascular disease in patients with end-stage renal disease. Clin Endocrinol (Oxf) 62: 242-249.

8. Burnett MS, Devaney JM, Adenika RJ, Lindsay R, Howard BV (2006) Cross-sectional associations of resistin, coronary heart disease, and insulin resistance. J Clin Endocrinol Metab 91: 64-68.

9. Steppan CM, Bailey ST, Bhat S, Brown EJ, Banerjee RR, et al. (2001) The hormone resistin links obesity to diabetes. Nature 409: 307-312.

10. Jung HS, Park KH, Cho YM, Chung SS, Cho HJ, et al. (2006) Resistin is secreted from macrophages in atheromas and promotes atherosclerosis. Cardiovasc Res 69: 76-85.

11. Rajala MW, Obici S, Scherer PE, Rossetti L (2003) Adipose-derived resistin and gut-derived resistin-like molecule-beta selectively impair insulin action on glucose production. J Clin Invest 111: 225-230.
12. Banerjee RR, Rangwala SM, Shapiro JS, Rich AS, Rhoades B, et al. (2004) Regulation of fasted blood glucose by resistin. Science 303: 1195-1198

13. Reilly MP, Lehrke M, Wolfe ML, Rohatgi A, Lazar MA, et al. (2005) Resistin is an inflammatory marker of atherosclerosis in humans. Circulation 111: 932 939

14. Ellington AA, Malik AR, Klee GG, Turner ST, Rule AD, et al. (2007) Association of plasma resistin with glomerular filtration rate and albuminuria in hypertensive adults. Hypertension 50: 708-714.

15. Efstathiou SP, Tsiakou AG, Tsioulos DI, Panagiotou TN, Pefanis AV, et al (2007) Prognostic significance of plasma resistin levels in patients with atherothrombotic ischemic stroke. Clin Chim Acta 378: 78-85.

16. Suzuki S, Takeishi Y, Niizeki T, Koyama Y, Kitahara T, et al. (2008) Pentraxin 3 , a new marker for vascular inflammation, predicts adverse clinical outcomes in patients with heart failure. Am Heart J 155: 75-81.

17. Lloyd-Jones DM, Larson MG, Leip EP, Beiser A, D'Agostino RB, et al. (2002) Lifetime risk for developing congestive heart failure: the Framingham Heart Study. Circulation 106: 3068-3072.

18. Roger VL, Weston SA, Redfield MM, Hellermann-Homan JP, Killian J, et al. (2004) Trends in heart failure incidence and survival in a community-based population. JAMA 292: 344-350.

19. Niizeki T, Takeishi $\mathrm{Y}$, Arimoto T, Okuyama H, Takabatake N, et al. (2005) Serum heart-type fatty acid binding protein predicts cardiac events in elderly patients with chronic heart failure. J Cardiol 46: 9-15.

20. Takeishi Y, Niizeki T, Arimoto T, Nozaki N, Hirono O, et al. (2007) Serum resistin is associated with high risk in patients with congestive heart failure--a novel link between metabolic signals and heart failure. Circ J 71: 460-464.

21. Schulze PC, Biolo A, Gopal D, Shahzad K, Balog J, et al. (2011) Dynamics in insulin resistance and plasma levels of adipokines in patients with acute decompensated and chronic stable heart failure. J Card Fail 17: 1004-1011.

22. Frankel DS, Vasan RS, D’Agostino RB Sr, Benjamin EJ, Levy D, et al. (2009) Resistin, adiponectin, and risk of heart failure the Framingham offspring study. J Am Coll Cardiol 53: 754-762.

23. Butler J, Kalogeropoulos A, Georgiopoulou V, Belue R, Rodondi N, et al. (2008) Incident heart failure prediction in the elderly: the health $A B C$ heart failure score. Circ Heart Fail 1: 125-133.

24. Butler J, Kalogeropoulos A, Georgiopoulou V, de Rekeneire N, Rodondi N, et al. (2009) Serum resistin concentrations and risk of new onset heart failure in older persons: the health, aging, and body composition (Health $A B C$ ) study. Arterioscler Thromb Vasc Biol 29: 1144-1149.

25. Zhang MH, Na B, Schiller NB, Whooley MA (2011) Association of resistin with heart failure and mortality in patients with stable coronary heart disease: data from the heart and soul study. J Card Fail 17: 24-30.

26. Rienstra M, Sun JX, Lubitz SA, Frankel DS, Vasan RS, et al. (2012) Plasma resistin, adiponectin, and risk of incident atrial fibrillation: the Framingham Offspring Study. Am Heart J 163: 119-124. 